\title{
Mensbeeld en zorgverlening
}

\section{Luc Anckaert}

In de concrete praktijk van de zorgverlening gaat men, of men dat nu wil of niet, altijd uit van een bepaalde visie op de mens, een visie die men zelden en ongaarne uitdrukkelijk aan de orde stelt. Nochtans, de hervormingen in hogescholen voor verpleegkundig onderwijs maken de vraag naar het achterliggend mensbeeld van de concrete verpleegkundige praktijk acuut. Zorgverlening is immers meer dan een 'neutrale' of abstracte techniek, waar aan de patiënt een reeks therapieën wordt geboden die de lichamelijke gezondheidstoestand kunnen stabiliseren, remediëren of verbeteren. Zorgverlening is meer dan de reparatie van de slecht functionerende raderen van de lichamelijke machinerie. De (ver)zorgende praktijk wordt gedragen door verpleegkundige theorieën die op hun beurt worden gedragen door mensvisies. ${ }^{2}$ In deze bijdrage schets ik de contouren van een mensvisie die relevant kan zijn voor de verpleegkundige theorie en praktijk.

Het uitgangspunt van mijn uiteenzetting is dat zorgverlening een concrete vorm is van intermenselijke relatie ${ }^{3}$, en dat men, om te kunnen begrijpen wat goede zorgverlening is, moet weten wat een relationeel mensbeeld impliceert. Eerst omschrijf ik enkele gangbare mensbeelden en hun effect op de concrete handelingspraktijk, daarna omschrijf ik wat een relationele mensvisie inhoudt en tenslotte formuleer ik enkele consequenties van deze relationele mensvisie.

\section{Mensbeeld en praktijk}

1. Elke handelingspraktijk wordt gedragen door al dan niet geëxpliciteerde mensvisies. De visie die wellicht het meest invloed heeft gehad op de geneeskundige praktijk is ongetwijfeld de Cartesiaanse mensvisie die ontstond in de Moderne Tijd. Vanaf toen ging men er immers impliciet van uit dat geest en lichaam twee volkomen ge- scheiden domeinen betreffen. ${ }^{4}$ Deze splitsing maakte een 'objectief' beeld van het menselijk lichaam mogelijk: het lichaam als een machine dat defect kan geraken en eventueel door een vakbekwaam persoon kan worden gerepareerd; het lichaam als 'dood' lichaam dat kan bestudeerd worden in al zijn kenmerken. Het Cartesiaanse mensbeeld leidde er toe dat gezondheid werd beschouwd als een afwezigheid van ziekten en gezondheidszorg als de reparatie van het disfunctionerende lichaam. Het bood aldus de mogelijkheid om, zonder rekening te houden met concrete mensen, nauwkeurig te bepalen waarin het ideaal van de zorgverlening bestaat: zoveel mogelijk resultaat boeken op het vlak van de gezondheid. Dit mensbeeld heeft er toe geleid dat menselijke individualiteit op de achtergrond verdween en alle aandacht ging naar de utilitaristische en kwantitatieve maximalisatie van de lichamelijke gezondheid. $^{5}$

2. Naast het Cartesiaans mensbeeld waarvan de sporen in de actuele gezondheidszorg nog steeds aanwijsbaar zijn, heeft er zich tegenwoordig een nieuwe mensvisie ontwikkeld: die van het vrije zichzelf ontwerpende individu. In tegenstelling met het Cartesiaanse mensbeeld dat omwille van zijn universeel en abstract karakter mensen in staat stelde de concrete doelstellingen van de zorgverlening a priori te bepalen, impliceert deze nieuwe mensvisie dat men de concrete zorgverlening telkens opnieuw zal moeten afstemmen op wat het concreet menselijk subject zelf als zinvol aanduidt. In plaats van de patiënt te beschouwen als een te genezen mechanisme treedt het individu in de nieuwe mensvisie naar voor als diegene die zelf beslist aan welke criteria de zorgverlening moet voldoen. In het kielzog van het existentialisme, bijvoorbeeld Sartre: "l'existence précède l'essence $e^{\prime 6}$ en bepaalde varianten van de humanisti- 
sche en fenomenologische denkrichtingen, werd de mens immers gaandeweg beschouwd als een zichzelf ontwerpende entiteit, een wezen dat zelf verantwoordelijk is voor zijn persoonlijk leven. Dit uitgangspunt impliceert dat niemand a priori kan stipuleren wat goed is voor 'de' mens in het algemeen. Telkens bepaalt het individu op zich wat het antwoord moet zijn op zijn of haar behoeften. In euthanasiedebatten kunnen vanuit deze intuïtie stellingen worden ingenomen die pleiten voor het absolute zelfbeschikkingsrecht van de patiënt.

In de mensvisie van personen die het zelfbeschikkingsrecht centraal stellen wordt niet het lichaam als 'dode' objectiviteit centraal gesteld maar wel de individuele waarden van het ik. De waarden die belangrijk zijn voor de praktijk worden vanuit deze mensvisie niet afgeleid vanuit een vooraf bepaald concept maar inductief gevonden in de singuliere situaties. Deze nieuwe mensvisie impliceert in die zin dat men in de zorgverlenende praktijk meer aandacht zal hebben en een groter respect zal opbrengen voor het waardepatroon van de patiënt. In plaats van de patiënt te behandelen als een willoos disfunctionerend mechanisme zullen de verzorgende instanties oog hebben voor de persoon van de patiënt. Toch zijn de gevolgen van deze nieuwe mensvisie niet zonder meer positief. Dit nieuwe mensbeeld kan zelfs bijzonder nefaste consequenties hebben. Dat het individu in staat is vrij te beslissen over wat goed voor hem of haar is, is immers een illusie. Menselijke waarden zijn immers niet louter het resultaat van individuele ontwerpen. Ze hebben vaak ook een objectief karakter, al is die objectiviteit niet toe te schrijven aan een of andere fysische of metafysische realiteit. Omwille van deze misvatting functioneert de nieuwe mensvisie in de concrete praktijk vaak als een soort ideologie die een realiteit van manipulatie en economische belangen maskeert.

3. Persoonlijk gaat mijn voorkeur uit naar een derde, jammer genoeg nog onvoldoende gangbare mensvisie, met name een relationele visie op de mens. ${ }^{7}$ De mens is niet uitsluitend het exemplaar van een voorafbepaalde entiteit waaraan normen voor de zorgverlening kunnen worden afgeleid. De mens is ook niet een volledig autonoom zelfbepalend wezen in het licht waarvan zorgverlening moet worden beschouwd als tegemoetkoming aan zelfontplooiing. Menszijn is veeleer een dynamisch en relationeel gebeuren. Zorgverlening moet zich daarom niet alleen richten op de medemens als zingevend maar ook als zinontvangend wezen. Het menselijk individu is een psychosomatische uniciteit (een ' $i k$ ') die fundamenteel in relatie staat met anderen (het 'jij' of de intersubjectieve relatie) en met een maatschappelijke context (het 'het' of de structurele relatie). De gezondheidszorg dient de noodzakelijke voorwaarden in verband met gezondheid voor deze drievoudige menselijke bestaanswijze te bevorderen, te herstellen of zo goed mogelijk te handhaven. Die stelling zal ik nu uitwerken in de volgende paragraaf.

\section{Het relationele mensbeeld en de zorgverlening}

Een relationeel mensbeeld veronderstelt dat de gezondheidszorg gericht is op de promotie van het volwaardige mens-zijn. Dit volwaardige leven kan niet voor eenieder vooraf bepaald worden. Zo zullen de te verwachten levensvormen voor een jonge patiënt anders zijn dan die voor een bejaarde, terminale kankerpatiënt. Nochtans is het wel mogelijk een soort coördinatensysteem te ontwikkelen, een netwerk van waarden, waarin de belangrijkste potentiële kansen van het menselijk leven een plaats hebben. ${ }^{8}$ Een aantal van deze kansen kunnen in het leven worden waargemaakt. Adequate zorg is er op gericht zoveel mogelijk van die kansen te vrijwaren.

Dit patroon of coördinatennet bevat de drie reeds vernoemde dimensies. De lijdende medemens wordt beschouwd als iemand met een lichamelijke en psychische identiteit. Elke mens heeft het recht zijn unieke persoon-zijn te beleven. Dit 
veronderstelt dat de zorg op meer dan het lichamelijke is gericht. De mensenrechtenverklaring drukt uit dat elkeen "in waarde en waardigheid als menselijke persoon gelijk is." Het recht op persoonlijke integriteit veronderstelt gezondheidszorg, maar ook een aangepaste levensstandaard, de nodige maatschappelijke diensten en een milieu of omgeving waarin de persoon tot zijn recht kan komen.

De relationele visie impliceert ook dat de mens niet uitsluitend op zelfontplooiing is gericht, maar dat de diepe menselijke zinservaringen een paradoxale structuur hebben. ${ }^{9}$ Men kan pas als mens in zijn waardigheid erkend worden door anderen die deze waardigheid principieel en feitelijk kunnen ontkennen. Een bevestiging van het mens-zijn is enkel mogelijk door wie deze bevestiging kan weigeren. Zoniet is de bevestiging hypocriet. Deze merkwaardige structuur betekent dat de menselijke zelfontplooiing niet de ultieme waardigheid van de mens uitdrukt. Het is niet omdat men over alles beschikt wat men zelf kan wensen, dat men gelukkig is. In de zinbeleving van ons mens-zijn zijn we afhankelijk van de anderen. De mens is een sociaal wezen. De zorgverlenende relatie moet de voorwaarden creëren om deze dubbelzinnige relatie te kunnen beleven.

Ten derde wordt in een relationele mensvisie ook verondersteld dat de mens deel uitmaakt van een maatschappelijk netwerk. De mens is ook een homo faber en een homo ludens, een arbeidend en een genietend wezen. De maatschappelijke positie van de mens is medebepalend voor zijn unieke persoonlijkheid. Het is duidelijk dat de 'sociale' verpleegkunde meer is dan een optie in het opleidingspakket maar een fundamentele dimensie van de zorgverlenende relatie uitdrukt.

Binnen dit netwerk wordt de mens begrepen als een wezen dat op relationele wijze zin aan zijn leven kan geven maar tevens de zin van dit leven ontvangt. De zin wordt niet alleen 'uitgevonden' maar ook 'ontdekt', de zin wordt niet alleen gemaakt, maar ook ontvangen. Levensbeschouwelijke aspecten nemen hier een belangrijke plaats in. De uitdaging naar de zorgverlenende relatie bestaat erin voor de lijdende medemens de kansen tot zinservaring te vrijwaren. Het weze duidelijk dat in deze optie ziekte en lijden niet als een ultiem failliet van het leven worden beschouwd. Of toch, ziekte en lijden zijn absurd, zonder zin. We kunnen immers niemand oprecht lijden toewensen om tot een zinservaring te komen. Maar misschien bestaat de uitdaging erin om ondanks lijden en ziekte toch tot een zinvol leven te komen. Misschien is de zorgverlening ook gericht op een menswaardig leven ondanks of in het lijden. De palliatieve zorg staat hier voor een belangrijke opgave. Misschien is het haar taak de drievoudige relationaliteit van het mens-zijn ten einde toe zo zinvol mogelijk te beleven door het lichaam met een mantel van mensgerichte zorg te omhullen in plaats van het lichaam te objectiveren met een eindeloze hardnekkigheid.

Deze summiere schets impliceert een grote verantwoordelijkheid voor de zorgverlener. Omgekeerd impliceert dit relationeel beeld ook dat men aandacht moet hebben voor de zorgverlener zelf. Hij of zij is geen buitenstaander die als een Atlas een wereld van verantwoordelijkheid moet torsen. De zorgverlener maakt zelf deel uit van het relationele netwerk van de mens. Daarom is zorgverlening, zoals reeds werd aangegeven, een concrete vorm van tussenmenselijke relatie. De zorgverlener is geen extraterrestrial wezen dat van buitenuit de kansen op een zinvol leven behoedt. Ook de zorgverlener is een relationele pool. Daarom is het belangrijk in een opleiding aandacht te besteden aan de persoonlijkheid van de zorgverlener en aan de interactie tussen de verschillende zorgverleners. De zorgverlenende relatie is hierdoor meer dan een technische relatie, maar een intermenselijk gebeuren waarbij het technische aspect van de zorg gedragen wordt door het lukken en het falen, door de open kansen en de gebroken situatie van de zorgverlener zelf. 


\section{Consequenties}

In dit laatste gedeelte worden enkele accenten geprofileerd die uit het voorgaande kunnen onthouden worden.

1. De gezondheid is niet de belangrijkste menselijke waarde, maar een zeer belangrijke voorwaarde tot mens-zijn. Met andere woorden, gezondheid is niet het hoogste menselijke goed. Dit betekent dat de gezondheidszorg op meer is gericht dan op de gezondheid. Ze dient de kansen te handhaven van het mens-zijn. Gezondheidszorg kan bijgevolg niet uitsluitend geëvalueerd worden in kwantitatieve cijfers van genezing..$^{10}$ Gezondheidszorg heeft eerder te maken met de kwaliteit van het relationele leven. Deze uitspraak beoogt het radicale tegendeel te zijn van een onderwaardering van het technische kunnen van de geneesen verpleegkunde. De gezondheidszorg is niet in de eerste plaats belangrijk omwille van de gezondheid. Neen, de gezondheidszorg is veel belangrijker dan dit. Ze is belangrijk omdat de kwaliteit en de menswaardigheid van het leven op het spel staat. Deze stelling betekent een promotie van de gezondheidszorg. De gezondheidszorg moet niet goed zijn, maar zeer goed. Niet omwille van zichzelf, maar omwille van de kwaliteit van het leven. Deze stelling kan bepaalde keuzen impliceren. Een zinvolle begeleiding van de stervende mens als relationeel wezen lijkt in dit perspectief belangrijker dan een doorgedreven acharnement thérapeutique of therapeutische hardnekkigheid die de dood als een kwantitatieve mislukking beschouwt.

2. De uniciteit van de menselijke waardigheid vraagt een transparantie in het gebeuren van de gezondheidszorg. De patiënt heeft principieel het recht te weten waar hij aan toe is. De waarheidsmededeling is een recht van de patiënt. Over de concrete modaliteiten waarop dit het beste gebeurt, kan gediscussieerd worden. Indien men de kwaliteit van het leven, en deze kwaliteit is meer dan gezondheid, wil beklemtonen, heeft de patiënt het recht te weten waar hij aan toe is. Een erkennen van de waardigheid van de mens betekent er niet voor terugschrikken een slecht-nieuws bericht te brengen. De confrontatie met een slecht-nieuws bericht vormt immers voor de patiënt de voorwaarde om te komen tot een zinvolle integratie van de eindigheid van het leven. Van de zorgverlener of zorgverleenster vergt een dergelijke confrontatie bepaalde communicatieve vaardigheden. Daarbij dient hij of zij aandachtig te zijn voor de psychische toestand van de patiënt. Een waarheidsmededeling mag immers nooit 'verpletterend' zijn.

3. Indien de mens als relationeel wezen wordt gerespecteerd, dienen er zich prangende vragen aan in verband met de materiële infrastructuur van de gezondheidszorg. Waarom kan de gezonde partner de kamer niet delen met de zieke partner? Waarom wordt het affectieve leven van partners zo goed als onmogelijk bij een opname? Wordt men een andere mens wanneer het zieke lichaam als voorwerp van gezondheidszorg wordt beschouwd? Dito opmerkingen zijn te maken in verband met psychiatrische problematieken. Men dient steeds te beseffen dat de materiële entourage de vorm van subjectiviteitsbeleving en menszijn mede bepaalt.

4. Daar de mens een sociaal en maatschappelijk wezen is, heeft ook hier de gezondheidszorg een belangrijke ondersteunende taak. Gezondheidszorg ten aanzien van een stervende bejaarde mag er bijvoorbeeld niet in bestaan in extremis allerlei bijkomende heelkundige ingrepen uit te voeren wanneer het stervensproces onherroepelijk is ingetreden, in tegenstelling tot de situatie van een jonge persoon wiens individuele en sociale levensverwachting nog bijzonder groot is. In het tweede geval is intense therapie vereist, maar in het eerste geval is het misschien verantwoord af te zien van een zuivere accumulatie van technische therapieën om meer aandacht te leggen op 
de care. Vanuit een kwantitatief oogpunt beschouwd, is deze stelling moeilijk te verantwoorden. Maar kwalitatief gezien is het zinvoller in het eerste geval te kiezen voor de optimalisering van de zinvolle beleving van het stervensproces dan voor een uitputtende situatie waarbij de patiënt sterft in een vervreemde omgeving.

5. De multidimensionele zinvolheid van het leven is vanuit een relationeel mensbeeld het richtsnoer van de gezondheidszorg. De gezondheidszorg is er niet omwille van zichzelf, ze is er ook niet omwille van een angst voor de dood die op allerlei wijzen gemaskeerd dient te worden. De gezondheidszorg dient de kwaliteit van het leven te bevorderen. Als dusdanig wordt ze gepromoveerd tot een belangrijke modaliteit van de intermenselijke relatie. Naar de verpleegkunde toe impliceert dit een bezinning over de fundamentele taak van de zorgverlening, een multidisciplinaire werking waarbij een geïntegreerde benadering van de patiënt voorop staat, een ernstige waardering van de verpleegkundige als persoon en tenslotte een besef van de enorme taak tot menselijkheid en tevens van de grenzen van de zorgverlenende praktijk.

De laatste overweging noopt tot een verdere reflectie. De verleiding is immers groot een ideaal-beeld te construeren dat alle contact met de realiteit heeft verloren. Tot nu toe heb ik geprobeerd te accentueren dat de zorgverlenende relatie gericht is op het welzijn, zowel lichamelijk-psychisch, relationeel als maatschappelijk. Bij de organisatie van de verpleegkunde staat men echter voor de paradox dat de zorg voor de individuele patiënt structureel gebeurt en maatschappelijk wordt georganiseerd en gefinancierd. Men staat met andere woorden voor de uitdaging de unieke situatie van de medemens op een veralgemenende wijze tegemoet te komen. ${ }^{11}$ Elke relationele mens is uniek maar terzelfdertijd is hij/zij ook gelijk. Het ideaal van de individuele zorg is maatschappelijk onhaalbaar. Vanuit deze paradox wil ik twee suggesties naar voren schuiven. a. De structurele context moet uitgebouwd worden als een concrete realisatie van de zorgverlening. De medemens blijft het centrale referentiepunt. Een verpleegkundige theorie en praktijk moet oog blijven hebben voor datgene waar het uiteindelijk om te doen is. Dit impliceert dat de praktische uitwerking van de zorgverlening meer moet zijn dan een kwantitatief toedienen van hoogstaande zorgverlening. Men dient dus een splitsing te vermijden tussen enerzijds de organisatie van de zorg en de individuele houding van de zorgverlener. In dit laatste geval zou de zorgverlener individueel overbelast worden. Deze splitsing kan misschien overwogen worden bij de studie van burn-out-syndromen. Een organisatie van de zorgverlening vanuit het geschetste perspectief dient gezien te worden als een geïntegreerd geheel dat multidisciplinair wordt opgevat en waarbij ten opzichte van de verpleegkundige een eigen taak en verantwoordelijkheid wordt toegekend. Een theoretisch concept en een praktische organisatie waarbij teamwork een belangrijke plaats inneemt is hierbij aangewezen. Ik wil dan ook pleiten voor een verdere uitbouw van de eigenheid van de verpleegkundige zorgverlening. Deze zorgverlening heeft een ander karakter en een andere verantwoordelijkheid dan de medische zorgverlening. Het kunnen twee complementaire disciplines zijn.

b. Wanneer men kiest op een geïntegreerde wijze als team zijn verantwoordelijkheid op te nemen voor de patiënt, betekent dit dat men de uitdaging aanneemt de structurele zorgverlening een menselijk gelaat te geven. De werkelijkheid zal evenwel nooit ideaal zijn. Elke individuele verpleegkundige heeft dan ook de taak de structurele tekortkomingen te remediëren, voor zover dat echter in zijn of haar mogelijkheden ligt. De tranen die door de mazen van de georganiseerde zorgverlening vallen, kunnen gedroogd worden door de concrete verpleegkundige. De goedheid van het georganiseerde verpleegkundige team sluit de kleine goedheid van de individuele zorgverlener niet uit. 


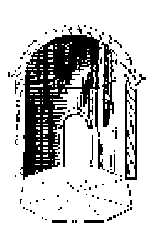

Noten

1. Herwerkte tekst van de openingslezing die werd uitgesproken op de pedagogische studiedag op 4 december 1995 aan de KATHO-Campus Roeselare, Departement Gezondheidszorg. Ik wil hier de collega's danken voor hun boeiende opmerkingen en hun ansporingen deze tekst te publiceren. De auteur $\left({ }^{\circ} 1962\right)$ behaalde het licentiaat in de Wijsbegeerte en het doctoraat in de Moraaltheologie aan de K.U.Leuven. Momenteel doceert hij Godsdienst, Ethiek en Filosofie aan de KATHO-campus Roeselare, het Instituut voor Verpleegkunde Ic Dien te Roeselare en Agora. Instituut voor christendom en wijsbegeerte (Leuven).

2. Voor de verpleegkundig theoretische kaders die aan de mensvisie kunnen worden gekoppeld of vanuit deze mensvisie onder kritiek kunnen worden geplaatst, verwijzen we naar het goede overzicht in G.C.M. EVERS, Theorieën en principes van verpleegkunde. Inleiding voor het wetenschappelijk onderwijs en onderzoek, Leuven/AssenMaastricht, Universitaire Pers Leuven/Van Gorcum, 1991.

3. Het personalistische denken, zoals het wordt uitgewerkt aan de Afdeling Moraaltheologie van de Theologische Faculteit van de KULeuven vormt de inspirerende achtergrond van deze uiteenzetting. De ethicus L. Janssens heeft hierbij baanbrekend werk geleverd. Vooral zijn artikel Kunstmatige inseminatie. Ethische beschouwingen, in Verpleegkundigen en gemeenschapszorg 35(1979) p. 220-244 biedt een bevattelijke uiteenzetting over de personalistische denkwijze in de ethiek. Zie ook: J.A. SELLING, ed., Personalist Morals. Essays in Honor of Professor Louis Janssens (BETL, 83), Leuven, University Press/Peeters, 1988. Voor een meer maatschappelijke uitwerking van het personalisme, zie: L. BOUCKAERT en G. BOUCKAERT, eds., Metafysiek en engagement. Een personalistische visie op gemeenschap en economie, Leuven, Acco, 1992. Vooral onder impuls van de professoren Schotsmans en Burggraeve werd deze denkwijze binnen de medische ethiek verder geëxploreerd en toegepast. Een concrete vrucht van dit onderzoek, toegepast op de zorgverlening en in het bijzonder op de verpleegkunde, vindt men bij A. VAN DER ARENDT \& C. GASTMANS, Ethisch zorg verlenen. Handboek van de verpleegkundige beroepen, Nijkerk, Intro, 1993. Naast deze eerste bron vonden we ook inspiratie in verscheidene teksten van Rosenzweig, Levinas en Ricœur.

4. In verband met de evolutie van de perceptie van het menselijke lichaam verwijzen we graag naar J.H. VAN DEN BERG, Het onderste kakebeen. Een metabletische les, in ID., De dingen en andere essays, Kapellen, 1994, p. 99-123 en meer fundamenteel ID., Het menselijk lichaam. 2 Volumes, Nijkerk, Callenbach, 1961 en M. FouCAULT, Geboorte van de kliniek. Een archeologie van de medische blik, Nijmegen, SUN, 1986.

5. Zie over dit utilitaristisch perspectief dat zich naast het Cartesianisme heeft ontwikkeld de kritische bemerkingen in P. SCHOTSMAns, Is het ten laste nemen van de gezondheidszorg door de solidariteit begrensd?, in J. HALLET, e.a., Solidariteit, gezondheid, etiek, Leuven, Garant, 1994, p. 33-47.

6. Cf. J.P. SARTRE, L'existentialisme est un humanisme, Parijs, Nagel, 1970 en in diens spoor het zelfontplooiingsdenken, kritisch bestudeerd in bv. R. BURGGRAEVE \& J. BULCKENS, eds., Waardenopvoeding in gelovig perspectief. Van zelfontplooiing naar verantwoordelijkheid, Leuven/Amersfoort, Acco, 1983.

7. De belangrijkste auteurs die hier inspiratie bieden zijn F. RosENZWEIG, Der Stern der Erlösung, Den Haag, Martinus Nijhoff, 1976; M. BUBER, Ich und Du, in ID., Das dialogische Prinzip, Darmstadt, Wissenschaftliche Buchgesellschaft, 1984, p. 7-136 en E. LeVINAS, De totaliteit en het Oneindige. Essay over de exterioriteit, Baarn, Ambo, 1987.

8. Naast het reeds vermelde denken van Janssens, verwijs ik ook graag naar E. SCHILLEBEECKX, Gerechtigheid en liefde. Genade en bevrijding, Bloemendaal, Nelissen, 1977, p. 671-683.

9. A. PePERZAK, Zoeken naar zin, Kapellen, Kok, 1990, p. 10-34; H. De DiJn \& A. BuRMS, De rationaliteit en haar grenzen, Leuven, Universitaire Pers, 1986, p. 27-33 en A. BURMS, Helpen en waarderen, in S. IJSSELING \& P. VAN HAUTE, eds., Deconstructie en ethiek, Leuven, 1992, p. 105-120 zijn voor dit vraagstuk zeer inspirerend.

10. Nochtans wordt het niet-genezen of het sterven als een failliet ervaren. Dat is misschien een van de redenen waarom de gestorven mens het ziekenhuis niet verlaat via de hoofdingang.

11. Deze problematiek wordt schitterend verwoord door Levinas. Cf. de reeds aangehaalde studie De vele gezichten van het kwaad. 